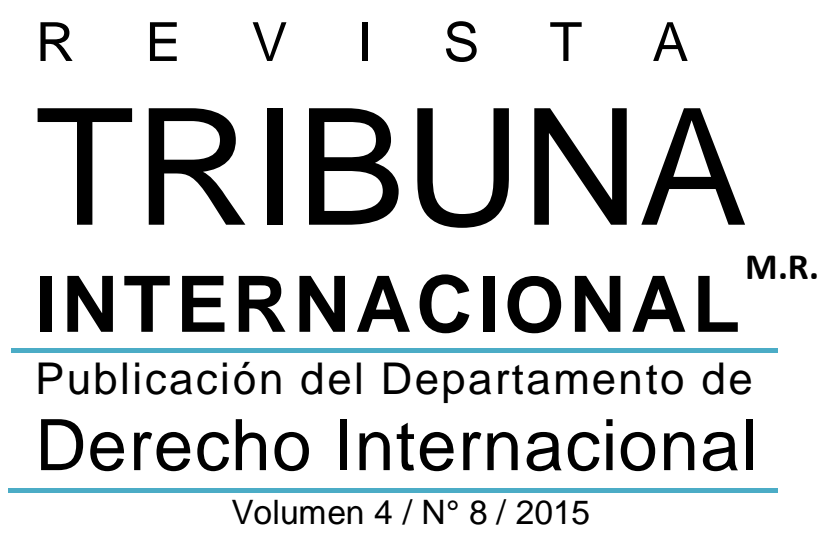

FACULTAD DE DERECHO 


\section{Rector de la Universidad de Chile}

Ennio Vivaldi Véjar

Av. Alameda Libertador Bernardo O'Higgins

1058, Santiago

\section{Representante legal}

Davor Harasic Yaksic

Decano de la Facultad de Derecho

Universidad de Chile

\section{Director Departamento Derecho}

Internacional

Edmundo Vargas Carreño

\section{Director (S) Revista Tribuna Internacional}

Mario Arnello Romo

\section{Editor General Revista Tribuna Internacional}

Luis Valentín Ferrada Walker

\section{Comité Editorial}

Íñigo Álvarez Gálvez (Universidad de Chile, Chile)

Gonzalo Aguilar (Universidad de Talca, Cbile)

José Carlos Fernández Rosas (Universidad

Complutense de Madrid, España)

Claudio Grossman (American University, EE.UU.)

Mattias Kumm (New York University, EE.UU.)

Hugo Llanos (Universidad Central, Chile)

Cecilia Medina (Universidad Diego Portales, Chile)

Elina Mereminskaya (Universidad de Chile, Chile)

Mónica Pinto (Universidad de Buenos Aires, Argentina)

\section{Fundador de la Revista Tribuna Internacional}

Mario Ramírez Necochea $†$

\section{Revista Tribuna Internacional M.R.}

Publicación del Departamento de Derecho Internacional de la Facultad de Derecho de la Universidad de Chile. Su objetivo es fomentar la reflexión, el debate, el análisis y la comunicación sobre el derecho internacional en forma pluralista y con rigor científico. Se publica cada semestre en los meses de junio y diciembre mediante convocatoria abierta a la publicación de artículos y monografías inéditos, comentarios de jurisprudencia, recensiones y comentarios de libros, en los campos de derecho internacional público y privado, derecho internacional de los derechos humanos y relaciones internacionales, tanto en castellano como inglés.

La Revista Tribuna Internacional fue creada por Decreto Exento No 8.466 de la Rectoría de la Universidad de Chile, de 22 de marzo del 2011.

Volumen 4/ No 8 / 2015

www.tribunainternacional.uchile.cl ISSN 0719-482X (versión en línea)

Departamento de Derecho Internacional Facultad de Derecho Universidad de Chile Av. Santa María 076, $4^{\circ}$ piso

Providencia, Santiago de Chile

\section{Diseño y producción:}

Facultad de Derecho

Universidad de Chile

Se autoriza la reproducción total o parcial del contenido de la publicación, siempre que se reconozca y cite el/ la/ los/ las autor/a/es/as y la publicación, no se realicen modificaciones a la obra y no se la utilice para fines comerciales. 


\title{
La unificación de Europa después de la Segunda Guerra Mundial: Retos y desafíos en un mundo globalizado
}

\author{
The Unification of Europe after the Second World War: Challenges in a Globalized World
}

\section{Walther L. Bernecker}

wlbernecker@aol.com

Catedrático de Historia Contemporánea de la Universidad Friedrich-Alexander de Nüremberg, Alemania.

Resumen: El ensayo analiza a grandes rasgos el proceso de unificación europea después de la Segunda Guerra Mundial, partiendo de la enorme desconfianza que reinaba en Europa en 1945 frente a Alemania. Explica cómo, paso a paso, esta desconfianza disminuyó a lo largo de las décadas, pero sin desaparecer completamente, lo que se puso nuevamente de manifiesto en el proceso de reunificación alemana después de la caída del Muro de Berlín. Resalta, además, que Europa se ha venido construyendo de crisis a crisis; todas estas crisis han contribuido, a fin de cuentas, a fortalecer la idea de la unidad Europea.

Palabras Claves: Europa - crisis - (des)confianza - ampliación - profundización.

Abstract: The essay analyzes the process of European unification after the Second World War. It starts with the enormous distrust that had most of the European states towards Germany, and it explains how, in the following decades, this distrust diminished slowly. Nevertheless, it did not disappear completely, what could be seen clearly in the process of German reunification after the fall of the Wall of Berlin. Furthermore, the essay underlines that the European Union has been built from one crisis to another, and all these crises finally have contributed to strengthen the idea of the European unity.

Keywords: Europe - crisis - (dis)trust - ampliation - profundization. 


\section{Introducción}

El título de esta contribución habla de "retos y desafíos en un mundo globalizado". Con razón se podría esperar que la contribución verse sobre las continuas crisis europeas a lo largo del último lustro: la crisis financiera del euro, la crisis de Ucrania y las relaciones de la Unión Europea con Rusia, la crisis de Grecia, la crisis muy actual de los centenares de miles de refugiados del Norte de África y de Oriente Medio. Y en efecto, el texto se referirá también a estas crisis y los desafíos que conllevan, existenciales para el futuro de Europa, y todos ellos síntomas de la globalización en la que está inserta la Unión Europea. Pero antes es necesario resaltar unos rasgos esenciales del proceso de unificación europeo después de la Segunda Guerra Mundial, sin los que no se puede entender el presente del continente y el comportamiento de los europeos en las crisis actuales ${ }^{1}$.

En relación con la crisis griega del año 2015, se ha insistido una y otra vez en que se ha perdido la confianza que es la base de la cooperación europea: los griegos, se dice, han perdido la confianza en las instituciones europeas, y los acreedores europeos han perdido la confianza en los griegos. Pero sin confianza no se puede construir un futuro común europeo. Esto, indudablemente, es cierto. Sin embargo, para valorar debidamente este axioma, hay que resaltar que en la base de la unificación europea no se hallaba la confianza de una nación con otra, sino justamente lo contrario: la unificación europea se ha construido sobre la base de la desconfianza, ante todo de la desconfianza de Francia frente a Alemania. Y esta desconfianza se puede observar desde el comienzo mismo, después de la Segunda Guerra, hasta prácticamente el presente. Valga un ejemplo para demostrar esta aseveración:

Pese a que la "idea de Europa" de los años de entreguerras había sido pervertida por el nacionalsocialismo, durante la Segunda Guerra Mundial surgió un nuevo concepto europeo en el seno de los miembros de la Resistencia francesa y en los gobiernos de exilio londinenses. Muchos miembros de la Resistencia y gobiernos de exilio no solo interpretaban su lucha contra Hitler desde la perspectiva del Estado nacional; se imaginaban una Europa de postguerra, en la cual una estrecha cooperación institucionalizada permitiría el control del nacionalismo

Además de la bibliografía que luego se cita para aspectos específicos, véase, entre otros, ALTRICHTER, Helmut y BerneCKer, Walther L. Historia de Europa en el siglo XX. Madrid, Marcial Pons, 2014; BERGLund, Sten et al. The Making of the European Union. Foundations, Institutions and Future Trends. Cheltenham, Edward Elgar Publishing Ltd., 2006; BRETHERTON, Charlotte et al. The European Union as a Global Actor. Londres, Routledge, 1999; KAISER, Wolfram et al. (eds.), European Enlargement. A Comparative History. Londres, Routledge, 2004; KRIESI, Hanspeter et al. (eds.), Nation and National Identity. The European Experience in Perspective. Zürich, Ruegger, 1999; MCAlLIsTER, Richard. European Union. A Historical and Political Survey. $2^{\mathrm{a}}$ ed. Edimburgo, Routledge, 2009; RichArdSON, Jeremy (ed.). European Union. Power and Policy-Making. $3^{\mathrm{a}}$ ed. Londres, Routledge, 2005; SENIOR NeLlo, Susan. The European Union: Economics, Policies and History. $2^{\mathrm{a}}$ ed. revisada. Maidenhead (Reino Unido), McGraw-Hill, 2008; STIRK, Peter. A History of European Integration since 1914. Reimpresión. Nueva York, Pinter, 2000; TRUYOL y SERRA, Antonio. Génesis y desarrollo de la Unión Europea (1979-2002). Madrid, Tecnos, 2002. 
exagerado ${ }^{2}$. Un orden de seguridad y paz duradero solo parecía ser posible sobre la base de entidades internacionales fuertes, que se controlaran mutuamente.

\section{Los comienzos post-bélicos}

Ya muy temprano, los líderes de la Résistance francesa se habían preguntado qué iba a ser de Alemania después de la guerra. Circularon numerosos planes de desindustrialización, desmilitarización y desmembramiento. Aunque no se puede hablar de una planificación francesa sistemática con respecto a Alemania, sí hubo algunas metas básicas, que en cierta manera representaban constantes de la política francesa. Sobre todo debía impedirse la restauración de un Estado alemán unificado con un gobierno central; en todo caso era imprescindible que el potencial de poder del desaparecido Imperio Alemán fuera aniquilado. Además, Francia estaba interesada en un sistema de seguridad colectiva frente a Alemania. A fines de 1944, el general Charles de Gaulle declaró: "En realidad, el destino de Alemania es el problema central del mundo. Para Francia es, a la vez, una cuestión de vida o muerte"3.

Debido al comienzo de la Guerra Fría, a más tardar desde 1947 los Estados Unidos y Gran Bretaña tenían la intención de fundar un Estado alemán occidental para poder contrarrestar los esfuerzos de los soviéticos que se estaban aprestando a instalar - de ser necesario, por la fuerzaregímenes comunistas en Europa oriental. Esta crítica situación europea también modificó las relaciones franco-alemanas y la política europeísta de Francia. Después de que Alemania occidental pudo obtener una ventaja estratégica en su posición debido al viraje global europeo hacia la Guerra Fría, para los franceses en adelante la integración europea se convirtió en el medio para poner coto a los alemanes de los que desconfiaban profundamente. Por otro lado, la concentración de importantes energías políticas hacia una unificación europea también concordaba con una conciencia ampliamente difundida en la población germano-occidental, ya que las perversiones nacionalistas del Tercer Reich y las experiencias negativas de la Segunda Guerra Mundial llevaron en la naciente República Federal a una crisis del sentimiento nacional, en la que la idea de la unificación europea se ofrecía como una alternativa deseable. Ya no debía ser en primer lugar la Nación, sino Europa la referencia de una emotividad colectiva.

También después de la fundación de la República Federal en 1949, la política francesa frente a Alemania siguió influida por temores y resentimientos ${ }^{4}$. En su política exterior, el Canciller alemán Konrad Adenauer estaba absolutamente dispuesto a tomar en consideración estos sentimientos franceses; pero esto significaba que debía hacer ciertas concesiones frente a la

\footnotetext{
BRUNN, Gerhard. Die europäische Einigung von 1945 bis heute. Stuttgart, Reclam, 2002, p. 29.

Lотн, Wilfried у Ріснт, Robert (eds.). De Gaulle, Deutschland und Europa. Opladen, Springer, 1991, p. 35.

POIDEVIN, Raymond y BARIÉTY, Jacques. Les relations franco-allemandes: 1815-1975. 2a ed., Paris, A. Colin, 1979, pp. 423-487.
} 
exigencia de seguridad francesa; ello, si quería lograr un objetivo de mayor alcance: reconquistar a mediano plazo libertad de acción e igualdad de derechos. El Canciller alemán consideraba la reconciliación franco-alemana como indispensable; solo así se podría integrar a la joven República Federal en el Occidente político.

En 1950, París tomó una iniciativa espectacular ${ }^{5}$. Volviendo sobre consideraciones de Jean Monnet, el Ministro de Relaciones Exteriores Robert Schuman propuso el 9 de mayo de aquel año supeditar la producción de carbón y acero francesa y alemana a una autoridad conjunta supranacional que también estaría abierta a otros países europeos. Esta propuesta perseguía varias metas, todas de central interés para Francia: por un lado, se trataba de la modernización de un ámbito esencial de la economía francesa, por el otro, del control del decisivo bastión industrial alemán. Además, esto sería un comienzo de la integración europea, que se venía discutiendo desde hacía buen rato. La propuesta de Schuman decía textualmente: "La solidaridad de la producción que se crea de este modo patentizará que cualquier guerra entre Francia y Alemania no solo será impensable, sino materialmente imposible”.

Adenauer inmediatamente aceptó “de todo corazón” la oferta de Schuman, puesto que las ideas básicas del Ministro de Relaciones Exteriores francés coincidían con las suyas. El control mutuo sobre el carbón y el acero, nacido de la desconfianza, contribuiría a desarrollar y fomentar la confianza entre los dos Estados. Con estas reflexiones de trasfondo, el verdadero adelanto en esta cuestión lo indujo la presión de los problemas que aún surgían de la "cuestión alemana”. ¿De qué manera se podía incorporar de forma estable a Alemania (occidental) en estructuras europeas (occidentales) que aún permanecerían vigentes cuando la ayuda del Plan Marshall hubiera llegado a su fin?

El Tratado firmado el 18 de abril de 1951 por Bélgica, Francia, Italia, Luxemburgo, los Países Bajos y la República Federal de Alemania sobre la fundación de la "Comunidad Europea para el Carbón y el Acero” (CECA) incursionaba de alguna manera en tierra incógnita europea, porque -con la Alta Autoridad, la Asamblea, el Consejo de Ministros y la Corte de Justiciacreaba por primera vez estructuras supranacionales. En los siguientes años, los Estados del Benelux propusieron -para dar un nuevo impulso al proyecto europeo- una reducción escalonada de diez años de duración de los impuestos de aduana internos y una creciente integración económica. Las negociaciones que siguieron a esta propuesta desembocaron finalmente, el 25 de marzo de 1957, en la firma en Roma del "Tratado sobre la Fundación de la Comunidad Económica Europea" (CEE). Después de su ratificación por los seis Estados fundadores, el Tratado entró en vigor el 1 de enero de 1958.

La ambiciosa meta de la Comunidad Económica Europea debía ser "fomentar, a través del establecimiento de un mercado común y del acercamiento gradual de la política económica de

5 Cfr. LeBLOND, Laurent. Frankreich und Deutschland seit 1945. Chronik einer besonderen Beziehung. Leipzig, Leipziger Uni-Vlg, 1999, p. 92.

6 BrunN, Die europäische Einigung..., op.cit., p. 71. 
los Estados miembros, un desarrollo armónico de la vida económica dentro de la Comunidad, una persistente y equilibrada expansión económica, una mayor estabilidad, una acelerada elevación del nivel de vida y relaciones más estrechas entre los Estados" que se habían asociado para formar la Comunidad ${ }^{7}$. Punto medular de la CEE era la unión aduanera, la paulatina supresión de los aranceles internos para una libre circulación de mercancías, que debía estar concluida para 1968. Traía como corolario la necesidad de coordinar los aranceles aduaneros externos, porque de lo contrario todas las mercaderías se agolparían para entrar por el lugar del arancel más bajo en el Mercado Común.

A pesar del enorme progreso que representaba la firma del Tratado de la CEE para la unificación europea, el año 1957 no fue el punto de inflexión hacia Europa, hacia la unión política; a lo sumo, era un nuevo intento después de la CECA y de la fracasada Comunidad Europea de Defensa en la primera mitad de los años cincuenta. Francia desconfiaba de todo lo que iba en dirección supranacional. También estaba cargada de desconfianza frente a las "manifestaciones de autonomía" de la Comisión Europea, se encontraba en permanente disputa por el desarrollo ulterior de la política agraria y tenía la mente puesta en la transición hacia decisiones por mayoría (y no por unanimidad), prevista para el año 1966. En julio de 1965, el general de Gaulle había retirado al representante francés del Consejo de Ministros, y con una política "de silla vacía" había dejado a este órgano sin la capacidad de ejercicio de sus funciones. La "Europa de las patrias" (L'Europe des patries) era su concepto orientador, y eso debía quedar así. Finalmente se logró imponer de hecho el principio de la mayoría en la toma de decisiones. Con esto, el "Compromiso de Luxemburgo" de momento cercenó las facultades de la Comisión y bloqueó todo desarrollo supranacional ulterior de la Comunidad durante las próximas dos décadas.

A comienzos de los años setenta, la consigna de las Comunidades Europeas (CE) era "conclusión, profundización, ampliación"; al final de esa década, empero, poco quedó de los ambiciosos planes, por todas partes se hablaba de "euroesclerosis". Al interior de la Comunidad aumentaron las mezquinas luchas por distribución de competencias, los problemas económicos de los Estados de la Comunidad llevaron a intentos proteccionistas de solución, las negociaciones de ampliación con los Estados de Europa meridional (España y Portugal) no avanzaban, y la Primera Ministra británica Margaret Thatcher con su fijación en los aportes financieros ingleses bloqueaba casi todas las iniciativas de política europea.

No sería sino en la primera mitad de los años ochenta cuando empezó una nueva dinámica en las Comunidades Europeas: por un lado, se impusieron cada vez más marcadamente políticas "neoliberales"; por el otro, en reiteradas ocasiones provinieron propuestas de las instituciones de las CE sobre cómo se podría intensificar la cooperación entre los gobiernos y mejorar la capacidad de acción de los órganos comunitarios. El Parlamento Europeo, elegido por primera

7 Cfr. el resumen del tratado en GASTEYger, Curt. Europa von der Spaltung zur Einigung. Darstellung und Dokumentation. Bonn, Bundeszentrale fur Politische Bildung, 2001, pp. 155-158. 
vez en 1979 mediante voto directo por los ciudadanos de los Estados miembros de las Comunidades, redujo en alguna medida el déficit democrático de las CE. En 1979 también se obtuvo un gran éxito en el ámbito de la política monetaria: después de numerosas sesiones y modificaciones de compromiso, los jefes de Estado y de gobierno europeos se pusieron de acuerdo sobre un Sistema Monetario Europeo (SME) que fijaba tipos de cambio estables entre los países de las Comunidades y que sería precursor del euro.

Un paso decisivo para la integración europea fue el Acta Única Europea (AUE) que se firmó en 1986. Pese a toda la justificada crítica, este convenio abrió el camino hacia una integración europea ulterior; estaba prevista una realización paulatina del Mercado Único para fines de 1992 y la orientación posterior de las Comunidades hacia el objetivo final de una Unión Europea. También en otro aspecto, el Acta Única Europea cobró importancia para el ciudadano europeo individual: a partir del "Informe Tindemans" de 1975, que se basaba en amplias encuestas, los "eurócratas" tenían en claro que los ciudadanos de Europa deseaban una Comunidad cercana a sus necesidades; se debía poder sentir y palpar a Europa, había que apelar no solo al intelecto, sino también al sentimiento y al corazón. Los reformadores se tomaron a pecho estas recomendaciones. Con el Acta Única Europea también trataron de crear una "Europa de los ciudadanos": la versión musical de Beethoven, en su novena sinfonía, de la Oda a la Alegría de Schiller, que ensalza la paz en Europa y expresa la superación de los límites estatales y sociales, fue declarada himno europeo; la bandera azul del Consejo de Europa con la guirnalda de estrellas doradas como símbolo de la Europa unificada se convirtió en la bandera oficial de las Comunidades; numerosos programas educativos y de juventud, como el Programa Erasmus, aumentaron la movilidad al interior de las Comunidades; además, se ampliaron las competencias del Parlamento Europeo. Junto a otras reformas, sobre todo la abolición de los controles de personas en las fronteras internas, debía posibilitarle al ciudadano europeo la "vivencia de Europa"; el Acuerdo de Schengen hacía posible viajar por Eurolandia casi libre de controles.

El desarrollo que se impulsó a mediados de los años ochenta desplegó una inesperada dinámica, la cual de una u otra forma influyó en casi todos los ámbitos del proceso de unificación europeo; la década de la "euroesclerosis" cedió a una fase de "euro-optimismo". Al promediar este tiempo se produjo, en 1989/90, el derrumbe del comunismo europeo oriental y las transformaciones de dimensiones impensadas a nivel de política mundial que ocurrieron a partir de ese acontecimiento también tuvieron por consecuencia que se desmoronara el orden europeo de postguerra. 


\section{De las Comunidades Europeas a la Unión Europea}

Pero antes de que la "revolución blanda" del bloque oriental cambiara radicalmente la situación política de Europa, fue abordado, desde 1987 en adelante, el proyecto de la unión monetaria europea. Si bien una única moneda europea era, en cierta manera, consecuencia necesaria del Mercado Único Europeo, también fue un objetivo que políticos franceses perseguían desde los años sesenta con el fin de obtener un "control” sobre el poder económico de la República Federal de Alemania. No sorprende, por lo tanto, que desde un comienzo el Presidente francés Francois Mitterand aspirara a establecer una unión económica y monetaria, mientras que el Canciller federal Helmut Kohl inicialmente reaccionó con reservas a una propuesta de esta naturaleza. Finalmente, el plan de una unión económica y monetaria fue aprobado por el Consejo Europeo en 1990, justo antes de las profundas transformaciones en Europa oriental, pero su implementación fue afectada por las turbulencias políticas a consecuencia de la caída del Muro de Berlín. Después del 9 de noviembre de 1989 la "cuestión alemana" se desarrolló tan impetuosamente que entre muchos políticos nuevamente resurgieron antiguos temores de una hegemonía alemana en Europa. Renació la desconfianza frente a Alemania - una desconfianza que ya había caracterizado el comienzo de la integración europea y que también estaría en el inicio de la moneda única europea. En los primeros meses del año 1990 se evidenciaba cada vez más que la reunificación alemana no iba a poder detenerse. El Canciller Kohl tuvo que hacer todo lo posible para tranquilizar a los vecinos y aliados de los alemanes. La mayor parte de los involucrados concordaba en que Alemania podría ser contrarrestada y controlada de la mejor forma mediante una profundización de la integración europea; la unificación alemana y la europea debían realizarse de forma simultánea ${ }^{8}$.

El deseo ampliamente extendido en Europa de incluir a la Alemania nuevamente unificada, más grande y más poderosa en el continente que estaba en proceso de unificarse, tuvo un efecto acelerador sobre la integración europea. Pero con ello no solo estaba a la orden del día una unión económica y monetaria; cada vez más a menudo se hablaba ahora de una gran unión política. El tratado que finalmente constituyó a la Unión Europea fue acordado a fines de 1991 en Maastricht. La Unión se propuso metas de gran alcance: por un lado, se trataba de estabilidad económica y social, de la eliminación de fronteras interiores y del establecimiento de una unión económica y monetaria; por el otro, se aspiraba a una política exterior y de seguridad común, a una cooperación cada vez más estrecha en las áreas de justicia y asuntos internos y (para fortalecer la identidad europea) a una ciudadanía de la Unión. De gran importancia iría a ser una innovación esencial: para fines de 1999 debía ser introducida la moneda común europea. Con ello, los Estados nacionales habían transferido una de sus competencias básicas a un nivel de decisión supranacional. Sin lugar a dudas, el Tratado de

8 Cfr. KNIPPING, Franz. Rom 25. März 1957. Die Einigung Europas. München, DTV, 2004. 
Maastricht llevó a una modificación cualitativa del complejo engranaje de las Comunidades Europeas.

El vínculo temporal de esta "profundización" de la integración europea con la discusión sobre posibles consecuencias de la reunificación alemana permite reconocer claramente que la estrecha inclusión de la República Federal en este proceso también tenía la intención de impedir que la Alemania fortalecida optase por caminos nacionalistas propios. Sobre todo Francia -junto con Gran Bretaña- mostró gran interés en la inclusión de su poderoso vecino oriental; en el cual, por lo visto, continuaba no confiando del todo.

En los primeros años noventa, la ratificación del Tratado de Maastricht se convirtió en un "euroespectáculo" desagradable, ya que hubo considerables problemas en varios países que evidenciaron que "Europa" de lejos no era el asunto de todos los ciudadanos europeos, que la Europa próxima al ciudadano todavía no existía, que el abismo entre algunos burócratas europeos desvinculados de la vida real y el proverbial "hombre de la calle" antes que disminuir había aumentado. La crisis sacudió a muchos, porque no se trataba tan solo de una "crisis de Maastricht", sino de una crisis de todo el proceso de integración europeo. Sin lugar a dudas, en los años noventa aumentó el número de voces escépticas precisamente respecto a este proceso de integración. A partir de Maastricht se volvieron claramente perceptibles para el ciudadano europeo los desafíos relacionados con la ampliación, el desarrollo de una política exterior y de seguridad común, así como con la reforma de las instituciones. Parece que después de años de una asociación comunitaria relativamente exitosa, la Unión Europea había llegado a un punto en el cual los Estados miembros estaban mucho menos dispuestos que antes a transferir más derechos de soberanía a Bruselas?.

Pero a pesar de todas las reticencias, con los tratados de Maastricht (1992), Ámsterdam (1997) y Niza (2000), el proceso de integración europeo avanzó tan vigorosamente que no solo de las Comunidades Europeas resultó la Unión Europea, sino que doce Estados de la Unión se dieron una moneda común, el euro, emprendieron otros progresos a la " velocidad de luz" (Javier Solana) en la política exterior y de seguridad común, y la Unión se preparó institucionalmente para la planeada ampliación hacia el Este. Esta ampliación debía integrar a los "países de transformación" que hasta el desplome del sistema soviético habían tenido un régimen comunista. Después de las diversas "revoluciones de terciopelo", en tan solo 15 años estos Estados reconstruyeron la democracia, erigiendo una economía de mercado en todo su territorio, renovando el sistema de educación y redescubriendo su propia cultura. Esta transformación rápida, y a la vez profunda, que se produjo sin violencia, fue única en la historia; complementó la dimensión histórica de la Comunidad Europea, la cual a diferencia de grandes imperios pasados y presentes ha sido construida en paz y armonía. Desde sus inicios

9 Gillingham, John. European Integration 1950-2003. Superstate or New Market Economy? Cambridge, Cambridge University Press, 2003. 
Revista Tribuna Internacional

Volumen $4 \cdot \mathrm{N}^{\circ} 8 \cdot 2015 \cdot$ pp. 15-25

ISSN 0719-482X (versión en línea)

en los años cincuenta del siglo XX ha desterrado la guerra para siempre de sus relaciones de vecindad.

Desde comienzos del siglo XXI se planteó la pregunta por la meta propiamente dicha de la unificación europea. Pragmáticamente bastante exitosa, durante décadas la Comunidad había llevado a cabo un paso de integración tras otro, sin jamás plantearse con fundamento la pregunta por su meta "final". Probablemente, fue justamente la indeterminación una condición esencial para los éxitos parciales de la historia de la unificación. Pero, cuantas más competencias fueron delegadas a organismos supranacionales, con tanta mayor urgencia se planteaba la pregunta por una visión esencial del futuro. Esta continúa siendo muy controvertida: varía -como desde siempre- entre una "Europa de las patrias" (organizada más bien de manera estatal-nacional) y los "Estados Unidos de Europa" (de orientación más bien supranacional), por lo tanto entre una federación de Estados más bien flexible y no muy cohesionada y un poderoso Estado federal. La Unión Europea actual no es ni lo uno ni lo otro, ni una organización internacional, como tampoco un Estado en el sentido clásico; su ulterior desarrollo deja abiertas todas las posibilidades ${ }^{10}$. Por de pronto, la Unión Europea puede mirar bastante satisfecha hacia atrás por el trabajo realizado hasta ahora: es una "comunidad de paz" sin demandas territoriales recíprocas y sin codicias sobre regiones distantes; éste es el verdadero novum, el "producto de exportación” más importante de la Comunidad.

\section{Retos y desafíos recientes}

Volviendo a la argumentación esgrimida al principio de este ensayo, se podría sostener que en cierta manera, mutatis mutandis, la historia se repite. En el origen de la unificación europea estaba -como se ha expuesto más arriba- la desconfianza, el deseo de un control mutuo de los Estados europeos. Esa parece ser de nuevo la actual situación europea que se puede ejemplificar con las grandes crisis europeas del último lustro: la crisis financiera del euro ha llevado en muchos países europeos a una intensificación no conocida antes de control y regulación bancaria; la anexión de Crimea por Rusia y la crisis de Ucrania han llevado a una generalizada desconfianza europea frente a Rusia, y con ello al resurgimiento de una situación en las relaciones exteriores europeas que se creía superada, ya que Europa, supuestamente, no tenía enemigos exteriores; la crisis de Grecia ha llevado no solo a una profunda desconfianza entre Grecia y sus socios europeos, que por muchos griegos hoy son contemplados no como socios, sino como adversarios, sino también a una división política en muchas sociedades europeas y a acalorados debates de una inusual intensidad emocional; la actualísima crisis de los refugiados no ha tenido por consecuencia un debate serio y solidario entre los Estados

10 Hartmann, Jürgen. Das Politische System der Europäischen Union. Eine Einführung. Frankfurt, Campus, 2001. 
europeos, sino todo lo contrario, ha llevado a tensiones entre los diferentes Estados, interesados cada uno en salvaguardar sus intereses nacionales. ¿Estamos, pues, en un momento especialmente crítico del desarrollo europeo, que puede hacer peligrar todo el proceso unificador?

Sin minusvalorar la importancia de todas estas crisis, hay que tener en cuenta un aspecto significativo del proceso unificador europeo: las crisis son marca y génesis de la Unión Europea. Hubo crisis de distintos tipos. Un tipo de crisis fueron las de crecimiento o ampliación. Con cada ampliación (y se han producido ya cinco desde 1957) hubo que cambiar el Tratado fundacional para adecuar el albergue a la familia multiplicada. A fin de cuentas, fueron operaciones de éxito, resultado de la visión expansiva del "club" y de la amplia demanda de ingreso. También hubo amargos reveses, como los rechazos en sendos referéndums del Tratado de Maastricht o del Tratado Constitucional, que hicieron necesarias readaptaciones. Otras crisis son las generadas por los disensos graves, incluso anteriores al Mercado Común, como cuando Francia en 1952-54 abortó la Comunidad Europea de Defensa; o cuando Margaret Thatcher bloqueó, en 1979, las instituciones reclamando un trato presupuestario más beneficioso para el Reino Unido al grito de "I want my money back". Un tercer tipo de crisis ha derivado de la disparidad de enfoques de política exterior, como en el caso de la guerra en los Balcanes, en los años noventa del siglo XX, en cierta manera también en el caso de la crisis de Ucrania, pero ante todo en el caso de la guerra de Irak, que dividió en 2003 a los gobiernos europeos entre halcones y palomas. Y finalmente, las crisis sistémicas, que afectan al núcleo duro de las competencias de la Unión y que ponen en vilo la estabilidad de la arquitectura política, jurídica e institucional común, como fue el caso en la (ya mencionada) "crisis de la silla vacía", cuando el general de Gaulle dictó el absentismo de Francia del Consejo de Ministros europeo, lo que paralizó a la Comunidad entre 1965 y 1968; y ante todo la crisis europea provocada por la gran recesión de los últimos años desencadenada por el estallido del banco Lehman Brothers. La actual secuencia griega es su capítulo más agónico.

Todas estas crisis se han superado gracias a un doble mecanismo: la conciencia de los costos de oportunidad, o sea el cálculo de que la alternativa de ruptura es siempre peor y más cara; y la voluntad de permanencia de los ciudadanos en la casa común. Porque por mucho que se critique a Europa en Europa misma, en el fondo, nadie quiere irse de ella. Jean Monnet dijo una vez que "los hombres no aceptan el cambio sino por necesidad" y que "no ven la necesidad sino en la crisis". Y las crisis no son (en palabras de Antonio Gramsci) sino que los momentos en que lo viejo no termina de morir y lo nuevo no acaba de nacer. Habrá que convenir en que la Unión Europea se ha fraguado a base de crisis entre los Estados-nación y el emergente proyecto supranacional. Y avanza superando estas crisis, algunas veces junto al abismo. Se podría decir que eso es una debilidad congénita: la ausencia de un modelo global finalista sobre el que moldearse. Pero también podría decirse que esa es su fortaleza, porque le permite adaptarse mediante la prueba y el error, trial and error, que es en cierta manera el método científico por excelencia. 


\section{Conclusiones}

De todas las crisis, la Unión Europea ha salido reforzada. Para repetir el argumento del comienzo de este ensayo: toda la integración europea es un grandioso ejercicio de confianza, crecida a lo largo de décadas que habían comenzado con claras muestras de desconfianza. La Comunidad no dispone de fuerzas coercitivas, y su autoridad se basa en la predisposición voluntaria asumida por un grupo de Estados orgullosos de haber superado las enemistades del pasado y de cumplir los tratados y las demás decisiones que van acordando. Se trata de tener confianza entre los socios, pero también de generarla en los ciudadanos, en las empresas que deciden invertir, o en el resto del mundo que confía que el proyecto europeo es creíble e irreversible. Es de esperar, pues, que la Unión Europea salga también de estas crisis, como de tantas otras, fortalecida, y que los europeos podamos seguir caminando juntos por esa senda que llamamos la "casa común europea". 